\title{
Spatial Patterns of Health Vulnerability to Heatwaves in Vietnam
}

Dang Ngoc Tran ${ }^{1,2}$, Van Quang Doan ${ }^{3}$, Vien Truong Nguyen ${ }^{2}$, Ansar Khan ${ }^{4}$, Phong K. Thai ${ }^{5}$, Huang Cunrui ${ }^{6}$, Cordia $\mathrm{Chu}^{7}$, Elena Schak ${ }^{7}$, Dung Phung ${ }^{7, *}$

${ }^{1}$ The Institute of Research and Development, Duy Tan University, Da Nang City, Vietnam

${ }^{2}$ Department of Environmental Health, University of Medicine and Pharmacy at Ho Chi Minh City, Ho Chi Minh, Vietnam

${ }^{3}$ Centre for Computational Sciences, the University of Tsukuba, Japan

${ }^{4}$ Department of Geography, Lalbaba College, Howrah, India

${ }^{5}$ Queensland Alliance for Environmental Health Sciences, The University of Queensland, Brisbane, QLD, 4102, Australia

${ }^{6}$ Health Management and Policy, School of Public Health, Sun Yat-Sen University, China

${ }^{7}$ Centre for Environment and Population Health, School of Medicine, Griffith University, Brisbane, Australia

*Corresponding authors:

Dung Phung

Email: d.phung@griffith.edu.au

Affiliation: School of Medicine, Griffith University, Gold Coast campus, Parklands Drive, Southport , QLD , 4222 


\begin{abstract}
The increasing frequency and intensity of heat events have weighty impacts on public health in Vietnam, but their effects vary across regions. In this study, we have applied a vulnerability assessment framework (VAF) to systematically assess the spatial pattern of health vulnerability to heatwaves in Vietnam. The VAF was computed as the function of three dimensions: exposure, sensitivity, and adaptive capacity, with the indicators for each dimension derived from the relevant literature, consultation with experts, and available data. An analytic hierarchy process (AHP) was used to determine the weight of indicators. Each province in Vietnam's vulnerability to the health impacts of heatwaves was evaluated by applying the Vulnerability Index, computed using 13 indicators (sensitivity index, 9; adaptive capacity index, 3; and exposure index, 1). As a result of this analysis, this study has identified heatwave vulnerability "hotspots", primarily in the Southeast, Central Highlands, and South-Central Coast of Vietnam. However, these hotspots are not necessarily the same as the area most vulnerable to climate change, because some areas that are more sensitive to heatwaves may have a higher capacity to adapt to them due of a host of factors including their population characteristics (eg rates of the elderly or children), socioeconomic and geographical conditions and the availability of air-conditioners. This kind of information, provided by the vulnerability index framework, allows policy makers to determine how to more efficiently allocate resources and devise appropriate interventions to minimise the impact of heatwaves with strategies tailored to each region of Vietnam.
\end{abstract}

Keywords: Vulnerability assessment; Health impacts; Developing countries; Heatwaves; Vietnam 


\section{Introduction}

Heatwaves are reported to be significantly associated with adverse health effects in different populations worldwide (Guo, Gasparrini et al. 2014, Hondula and Barnett 2014, Gasparrini, Guo et al. 2015). Previous studies have indicated that heatwaves have significantly increased the risk of both morbidity (Michelozzi, Accetta et al. 2009, Phung, Guo et al. 2016, Phung, Chu et al. 2017) and mortality (Huang, Barnett et al. 2012, Guo, Gasparrini et al. 2014, Yang, Li et al. 2015). The health consequences associated with heatwaves are a wide range of communicable (Milazzo, Giles et al. 2016, Lee, Nguyen et al. 2017, Xiang, Hansen et al. 2018) and non-communicable diseases (Ebi, Exuzides et al. 2004, Turner, Barnett et al. 2012, Phung, Guo et al. 2015). However, the impacts of heatwaves vary considerably across different locations and at differing scales (Knowlton, Rotkin-Ellman et al. 2009, Page, Hajat et al. 2012) due to the variability of localised microclimates, resulting from the complexities of their physical and built environments (Bassil, Cole et al. 2009), socioeconomic development (Rey, Fouillet et al. 2009), and adaptation strategies (Huang, Barnett et al. 2011). For example, a spatial variation in at-risk individuals across a city may result in some of its areas having a higher population sensitivity to temperature than others (Reid, O'Neill et al. 2009, Hondula, Davis et al. 2012). Therefore, identifying populations who are more vulnerable to heat-related mortality and morbidity is essential in order to manage the public health risk of heat stress.

The assessment of health vulnerability is, however, a complex exercise, which requires the consideration of a host of locality-dependent physiological variables as well as other social and environmental factors (Aubrecht and Ozceylan 2013). Vulnerability is considered a function of the level of exposure to heatwaves, the level of sensitivity to an heatwave, and a population's level of adaptive capacity (McCarthy, Canziani et al. 2001, Oppenheimer, Campos et al. 2014). In this framework, 'exposure' is defined as the nature and degree to which a system is exposed to heatwaves; 'sensitivity' is the degree to which a system is affected by heatwaves; while 'adaptive 
capacity' is a system's ability to adjust to a heatwave, to moderate potential damage, to take advantage of opportunities, or to cope with consequences (Zhu, Liu et al. 2014).

Vietnam, a developing country, is one of South-East Asia's most vulnerable countries to climate change (Yusuf and Francisco 2009). The annual average temperature in Vietnam is anticipated to increase from $1.1-1.9^{\circ} \mathrm{C}$ to $2.1-3.6^{\circ} \mathrm{C}$ by the end of the $21^{\text {st }}$ Century (UNEP 2009). Temperatures of over $40^{\circ} \mathrm{C}$ have been recorded recently in the main regions of Vietnam (INPONRE 2009), and the frequency of days with an average temperature above $35^{\circ} \mathrm{C}$ will increase in the future in highly vulnerable regions such as the Mekong Delta area (Chaudhry and Ruysschaert 2008). Previous studies in Vietnam have reported the association between exposure to high temperatures and heatwaves, with increases in the risk of water and vector-borne diseases, cardiovascular and respiratory diseases, and the risk of hospital admissions among young children (Giang, Dung et al. 2014, Phung, Huang et al. 2014, Xuan, Egondi et al. 2014, Xuan, Hau et al. 2014, Phung, Guo et al. 2015, Phung, Huang et al. 2015, Phung, Rutherford et al. 2015, Phung, Guo et al. 2016). There have been some preliminary reports on the impact of climate changes and adaptation measures in Vietnam, as summarised by the Research Center for Rural Population and Health (2011) (RCRPH), but no study has been conducted to map the spatial patterns of health vulnerability due to heatwaves across Vietnam.

This study aims to spatially assess the expert-driven health vulnerability to heatwaves across Vietnam by integrating heatwave exposure and related vulnerability indexes that reflect each region's health, socio-economic and environmental characteristics.

\section{Materials and methods}

\subsection{Vulnerability assessment framework}

For this study, we have referred to the vulnerability assessment framework developed by The Intergovernmental Panel on Climate Change (IPCC) (McCarthy, Canziani et al. 2001) and applied 
evaluations of vulnerability to factors relating to climate change elsewhere (Zhu, Liu et al. 2014) (Fig. 1).

\subsection{Data collection}

Temperature data were collected from the ERA-Interim Reanalysis Archive of the European Centre for Medium-Range Weather Forecasts. ERA-Interim is a global atmospheric reanalysis from 1979, and is continuously updated in real time. Reanalysis consists of the past weather data reconstructed from observation data. Through a variety of methods, observations from various instruments are combined onto a regularly spaced grid of data. The spatial resolution of the ERAInterim dataset is approximately $0.7^{\circ}$ horizontally $(80 \mathrm{~km}$ at the Equator) on 60 vertical levels from the surface up to $0.1 \mathrm{hPa}$ (approximately $37 \mathrm{~km}$ from the ground). In this study, only daily air temperature data collected near to the ground over 13 years $(2005$ - 2017) in Vietnam were used for heatwave analysis.

The pools of sensitivity and adaptive capacity indices were generated from indicators with reference to a range of existing studies and consultations with expert stakeholders and based on the availability of data. The stakeholders included health, environmental, and social experts from management agencies and scientific institutions (i.e. ministry of health, ministry of environment, Hanoi university of public health, etc.). This study is one of a bigger research project in climate change and health in the Mekong Delta Region. The project was approved by the ethical committee of Griffith University (GU Ref No: ENV/23/15/HREC) and Health and Environment Management Agency, the leading agency of health sector responsible for climate change and health in Vietnam (1290/MT-SKCD). The sensitivity indicators include: population density, \% of elderly ( $>65$ year olds) and children ( $<15$ year olds), $\%$ female population, $\%$ of urban population, $\%$ of illiterate people among $>15$ year olds, $\%$ of unemployed, $\%$ of poverty households, $\%$ of households with low access to hygienic water. Adaptive capacity indicators include: number of health staff per 10000 population, $\%$ of households with air conditioning, and \% of green areas. We extracted the data of these indicators at the provincial scale from the database of the Vietnam General Statistics Office (GSO 2014), 
Vietnam National Census (VN GSO 2008), and Health Statistic Yearbook (HSY 2013). The green areas were extracted from the Moderate Resolution Imaging Spectroradiometer (MODIS) land cover dataset, which were created from supervised classifications of spectro-temporal features from the MODIS reflectance data (Friedl et al. 2010).

\subsection{Data analysis:}

\subsubsection{Heatwave definition and assessment}

In this study, as with our previous study in Vietnam, we defined a 'heatwave' as three or more consecutive days where the average temperature is above the $95^{\text {th }}$ percentile value obtained from the provincial weather station or proxy (Phung, Guo et al. 2015, Phung, Guo et al. 2016). Then, the exposure index, which is the magnitude of heatwaves, was the sum-up of multiplicative products between heatwave events and number of heatwave days during the study period. The period of study was from 2005 to 2017, during which the magnitude of heatwaves was calculated for the summer (May to August) in the Northern provinces, which are located in a sub-tropical climate, and for the whole year in the Southern provinces, which are located in a tropical climate.

\subsubsection{Sensitivity and adaptive capacity assessment}

For sensitivity and adaptive capacity dimensions, ten stakeholder experts in the areas of public health, and social and environmental science were invited to evaluate the relative importance of all indicators. We then used the Analytic Hierarchy Process (AHP) to generate a weight for each indicator based on their relative importance in each dimension. An expert could subjectively judge the relative importance between indicators following a 1-9 fundamental scale, in which ' 1 ' indicates equal importance and '9' indicates extreme importance. A judgement matrix was then obtained for each dimension from each expert. We tested the consistency using a consistency ratio (CR) to examine whether the sorting results were logically consistent. The acceptable scoring results were considered when $\mathrm{CR}<0.10$. The final weight for each indicator was an average result given by all experts. The details of AHP have been described elsewhere (Whitaker 2007, Zhu, Liu et al. 2014, 
Mu and Pereyra-Rojas 2017). Finally, the sensitivity index (SI) and adaptive capacity index (AI) were calculated using the following equations:

$$
\begin{gathered}
S I=\sum_{1}^{t} \omega_{t} S_{t} \\
A I=\sum_{1}^{i} \omega_{i} A_{i}
\end{gathered}
$$

where $S I$ is Sensitivity Index; $S_{t}$ is sensitivity indicators from 1 to $\mathrm{t}$; $\omega_{t}$ is the weight of each sensitivity indicator; $A I$ is Adaptive Capacity Index; $A_{i}$ is an adaptive capacity indicator from 1 to $\mathrm{i}$, and $\omega_{i}$ is the weight of each adaptive capacity indicator.

\subsubsection{Calculation of Vulnerability Index (VI)}

We referred the framework recognized by IPCC (Eq. 3), in which vulnerability was a function of exposure, sensitivity, and adaptive capacity (McCarthy, Canziani et al. 2001). To reduce the high heterogeneity of index values, we normalised the values of the Exposure Index (EI), Sensitivity Index (SI) and Adaptive Capacity Index (AI) by maximum and minimum records ([value]-[min]/[max]-[min]) in order to have an index domain ranging from 0 to 1.

Vulnerability Index (VI) was computed as the function of three dimensions: exposure, sensitivity, and adaptive capacity (Eq. 3). A multiplicative model was used to evaluate the VI for each province in Vietnam, using the following formula:

$$
V I_{j}=E I_{j} \times \frac{\left(1+S I_{j}+A I_{j}\right)}{n}
$$

$V I_{j}$ is the overall health vulnerability index to heatwave in province $\mathrm{j}, E I_{j}$ is the level of exposure to heatwave for province $\mathrm{j}, S I_{j}$ is the sensitivity index for province $\mathrm{j}, A I_{j}$ is the adaptive capacity index for province $\mathrm{j}$, and $\mathrm{n}$ is the total number of components included in the SI and AI. The higher the AI value, the less adverse the impact this province would be subject to during heatwaves. The higher SI value, the higher the impact this province would be subject to during the heatwaves. The distribution of VIs of 63 provinces across Vietnam is displayed below in Fig. 3.

\section{Results}

\subsection{Characteristics of heatwaves and vulnerability indicators}




\section{Heatwaves}

The temperature threshold and the total number of heatwave days during the study period (2005-2017) in different provinces of Vietnam are presented in Fig. 2A and Fig. S1. The temperature thresholds for heatwaves at the $95^{\text {th }}$ percentile values ranged from $24.5^{\circ} \mathrm{C}$ to $32.4^{\circ} \mathrm{C}$ with a mean of $29.5^{\circ} \mathrm{C}$. The lowest average thresholds were recorded in the mountainous $\left(27.3^{\circ} \mathrm{C}\right)$ and Highland regions $\left(27.1^{\circ} \mathrm{C}\right)$; whereas the highest average thresholds were found at the provinces in Red River Delta $\left(31.9^{\circ} \mathrm{C}\right)$. The thresholds of other regions are decreasing in the following order: North-Central provinces $\left(30.1^{\circ} \mathrm{C}\right)$, Mekong Delta $\left(29.7^{\circ} \mathrm{C}\right)$ and South-eastern provinces $\left(29.7^{\circ} \mathrm{C}\right)$, North-Eastern provinces $\left(29.4^{\circ} \mathrm{C}\right)$, and South-Central provinces $\left(28.9^{\circ} \mathrm{C}\right)$.

The Southern part of the country had a higher number of heatwave days during the study period (2005-2017) than the Northern part (Fig. 2). By region, the largest average number of heatwave days was found in South-Eastern provinces (122 days), followed by the Mekong Delta provinces (115 days), the South-Central provinces (83 days), and Highland provinces (78 days). The Northern mountainous region had the lowest average number of heatwave days, ranging from 18 to 30 days (Fig. 2A).

\section{Sensitivity and Adaptive Capacity indicators}

Finally, a total of 11 indicators ( 8 for sensitivity and 3 for adaptive capacity) were set to be used in our vulnerability assessment framework for heatwaves at the provincial level across Vietnam. The descriptive characteristics of the indicators are presented in Table 1.

\subsection{Results of the AHP method}

The weights of indicators were first evaluated by each expert using the AHP method, and then the average weight of each indicator was computed (Table 2). The result was consistent with all CRs $<0.1$. Regarding sensitivity issues, the sensitive populations, including children and the elderly, were considered to be the most important indicators by experts, with the next most important indicators comprising population density and lower access to safe water. For adaptive capacity, the prevalence of households with air conditioning was considered to be the most effective indicator for 
reducing the health risk of heatwaves. Figure $2 \mathrm{~B}$ and $2 \mathrm{C}$ show the results in the spatial distributions of the sensitivity and adaptive capacity indices.

Figure 3 shows the distribution of the Vulnerability Index by province. The patterns of VIs are inclined toward to the Southern region, of which the provinces in South central region are likely the most vulnerable to heatwave-related health risk. The next most vulnerable regions are the SouthEastern and South-Western provinces. The least vulnerable groups were found to be the NorthWestern provinces, which are mountainous areas, and North-Eastern provinces, which are NorthCoastal areas.

\section{Discussion}

Vietnam is severely affected by climate change (Field, Barros et al. 2014) in a variety of ways including its agricultural production, social-economic structures, development processes, and security issues (i.e. food, water, energy, public safety, as well as political, cultural, economic, diplomatic and commercial security) (MONRE 2008, MONRE 2009, MONRE 2013, MONRE 2016). There is a paucity of research on health vulnerability assessments for climate change at the national scale. To the best of our knowledge, this study is the first to quantify health vulnerability to heatwaves across Vietnam.

\subsection{Vulnerability assessment methods}

There are several methods for assessing vulnerability to climate change (Bao, Li et al. 2015). Since health impacts have different expressions, vulnerability indicators vary accordingly. However, vulnerability is often determined by three dimensions including exposure, sensitivity, and adaptive capacity (RCRPH 2011, Aubrecht and Ozceylan 2013, Dong, Liu et al. 2014, Zhu, Liu et al. 2014). The VAF used in our study also utilised those dimensions and has been developed and adapted by the IPCC to quantify health vulnerability in different countries (McCarthy, Canziani et al. 2001, Parry, Parry et al. 2007). 
Heatwaves are a common indicator for exposure in heat vulnerability assessment. Heatwave definitions often vary across studies in the form of the number of consecutive days that exceed a threshold temperature, the threshold temperature used, and severity (RCRPH 2011, Aubrecht and Ozceylan 2013, Dong, Liu et al. 2014, Zhu, Liu et al. 2014). In 2010, a WHO report in Vietnam defined a heatwave as a day having a temperature above $37^{\circ} \mathrm{C}$, while the World Meteorological Organization (WMO) defines a heatwave as a period in which the daily maximum temperature is higher than $32^{\circ} \mathrm{C}$ for more than three continuous days. Recent studies on heatwave vulnerability have applied similar definitions to different temperature thresholds (Aubrecht and Ozceylan 2013, Dong, Liu et al. 2014, Zhu, Liu et al. 2014). Our study takes into account the variance in what is considered a 'heatwave' in different locations. As such, we use a common definition from the literature, according to which a heatwave is 'three or more consecutive days where the average temperature is above the $95^{\text {th }}$ percentile value obtained from the provincial weather station or proxy'.

In heatwave vulnerability studies, common indicators used in previous studies for SI and AI include population density, percentage of children and elderly, the rate of people living alone, education, economic conditions (income/GDP), the unemployment rate, immigrant population rate, health staff rate, and land use/cover. Structures for sensitivity and adaptive capacity assessment have not been clearly identified or heterogeneous between studies (Aubrecht and Ozceylan 2013, Dong, Liu et al. 2014, Zhu, Liu et al. 2014). In our study, some indicators were applied similarly to previous studies, however there were also differences due to the availability of data. For a more complete assessment in our study, ten stakeholder experts added three available indicators including the urban population rate, the rate of households with lower access to safe water (for SI), and the rate of households that have air conditioning (for AI).

Previously, un-weighted quantitative aggregation and indicator standardisation have commonly been used to calculate indices from a data pool. Un-weighted quantitative aggregation has been a common approach but it could not consider the weighted contribution of indicators in assessment (Aubrecht and Ozceylan 2013, Dong, Liu et al. 2014). Although each indicator have 
significant impact, the contribution of each indicator is unequal. Applying weighted contribution will adjust the impact of each indicator and improve estimates. The AHP approach was used to generate a weight for each indicator based on the relative importance of indicators in each dimension. This approach has also been applied in another study in Guangdong, China (Zhu, Liu et al. 2014). Objective aggregate indices play an important role in simplifying multiple indicators into an index (Vincent 2004). Although this minimises subjectivity compared to the un-weighted approach, experts' subjectivity is not eliminated in the AHP approach. In our study, ten experts in the areas of public health, social and environmental science participated in the relative importance evaluation process to give multi-dimensional perspectives from many science areas.

The recruitment process and availability of the indicators may cause the differences in vulnerability indicators, which can lead to problems when comparing published literature. However, despite the different indicators, the availability and the specificity of indicators will play an important role in developing adaptation strategies for a specific location.

\subsection{Spatial distribution of Heatwaves}

Our study showed that in Vietnam the number of heatwave days increased continuously from North to South (Fig. 2), corresponding to the humid subtropical, monsoon, and tropical savanna climate zones (UNDP 2016). In addition, the spatial distribution of heatwaves was associated with the annual average temperatures in the Southern provinces (the Mekong River Delta, Southeast, South Central Coast, and Central Highlands) being higher than those in the Northern provinces (North Central Coast, Red River Delta, Northeast, Northwest). Visual data from our study and previous study showed that Southern provinces suffer from a higher temperature burden than Northern provinces (WBG 2018). Following global trends, it is estimated that until 2050, the average temperature of the Southern provinces will increase by $1.4{ }^{\circ} \mathrm{C}$ to $1.8{ }^{\circ} \mathrm{C}$ (Ngo, Kieu et al. 2014). With a high existing temperature and the coming strong increase to it, the Southeast will become the region with the highest level of exposure to temperature, including heatwave events.

\subsection{Spatial distribution of Sensitivity}


According to research conducted by WHO in 2010, the area most sensitive to the health impacts of climate change is the Northwest region of Vietnam (RCRPH 2011). All provinces in the Northwest have had a Health Sensitivity Index from 0.82 to 1 on the Health Sensitivity Scale from 0 to 1 . Although some indicators in our study are different from those used in the WHO study, the findings are similar (RCRPH 2011). The Northeast and Northwest are characterised by rugged alpine terrain, which creates many difficulties for its socio-economic development. Meanwhile, the provinces along the Mekong River (the Mekong River Delta) are highly sensitive to the impact of heatwaves, which is attributed to the high elderly population, the lack of hygienic water, and unemployment (Fig. S2). A notable finding of our study is that most major cities are highly sensitive to heatwaves, including Hanoi (Red river Delta), Da Nang (Central Coast), Ho Chi Minh (Southeast), and Can Tho (Mekong river Delta). Statistics in 2017 showed that these 4 cities have the highest population density in Vietnam, especially Ho Chi Minh city and Ha Noi (GSO 2014), which greatly contributes to their high sensitivity to heatwaves. In addition, the high proportion of urban topography and of sub-populations of children and the elderly are also typical contributors to the major cities' sensitivity. Similar distributions of sensitivity were also found in previous studies (Zhu, Liu et al. 2014, He, Ma et al. 2019). The high population density means that a larger population size is affected by extreme heat events in a narrow space. Additionally, high population density is often accompanied by infrastructure development and urbanisation, which creates an urban heat island effect, resulting in urban settings having a more serious exposure to heatwaves (Campbell, Remenyi et al. 2018).

\subsection{Spatial distribution of adaptive capacity}

Another interesting finding from our study is that while the Northeast and Northwest had poor adaptive capacity to climate change, as reported previously (RCRPH 2011), those regions have high adaptive capacity to heatwaves due to their high green area coverage rate. The areas with poor adaptive capacity to heatwaves are mainly in the Central Coast and Central Highlands, despite their high green area coverage rate. The poor adaptive capacity of these areas was due to the near absence 
of household air conditioners (Fig. S3), which have proved to be one of the most effective measures to mitigate the impacts of heatwaves (Matthies, Bickler et al. 2008). Major cities where there is a high proportion of households with air conditioners, including Ho Chi Minh city and Hanoi, have a high adaptive capacity. The same factor helps to make the Mekong River Delta's adaptability higher than in the Central Coast and Central Highlands, despite it having a lower rate of green area coverage. Although major cities are often more sensitive to heatwaves they are better equipped to adapt to extreme heat events because of their better socio-economic conditions (Zhu, Liu et al. 2014, He, Ma et al. 2019).

\subsection{Spatial distribution of vulnerability}

According to the WHO Report on Health Vulnerability to Climate Change in Vietnam, the regions where health is most highly vulnerable to climate change were Vietnam's Northwest, Red River Delta, Central Coast, and Central Highlands, with heatwaves being one of the indicators of exposure index (RCRPH 2011). In contrast, our study found that Vietnam's Southern areas (the South Central Coast, Central Highlands, Southeast, and Mekong River Delta) are more vulnerable to the health impact of heatwaves than the Northern areas (Northwest, Northeast, Red river Delta, and North Central Coast). According to our study, the health vulnerability map and heatwave exposure map have a very strong correlation. As such, the Red River Delta, Northeast, and Northwest have low levels of vulnerability because of their low heatwave exposure levels and high adaptive capacities. The Southeast, Central Highlands and South Central Coast have a combination of a high level of exposure, high level of sensitivity, and limited adaptive capacity to heatwaves, making them the regions with the highest level of vulnerability in Vietnam. In our study, the major cities receive a lower vulnerability index compared with their neighbouring provinces due to their high adaptability, as reported previously in other studies (RCRPH 2011, Zhu, Liu et al. 2014, He, Ma et al. 2019). Thus despite their high sensitivity, their socio-economic conditions provide them with a stronger adaptive capacity, which has significantly reduced vulnerability in urban areas.

\section{Future perspectives}


Following the trends of global climate change, the frequency and intensity of heatwaves will continue to increase in the future. According to the Intergovernmental Panel on Climate Change, Southeast Asia is one of the most high-risk regions, with heatwaves in all climate change scenarios (Campbell, Remenyi et al. 2018). Located in this high-risk region, Vietnam has to develop strategies to adapt to future extreme heat events. It is necessary to utilise the VAF for heatwaves based on AI, SI, and EI to identify the most vulnerable areas in order to ensure that they receive appropriate resources and interventions to minimise the impact of heatwaves. However, there needs to be continuous assessment of these indices because SI and AI can vary as a result of population trends. For example, the trend of rural-to-urban migration of working-age people leads to rapid urban population growth, while having the elderly and children remain in the countryside increases sensitivity in these rural areas. The increase of the urban population also puts great pressure on the health system. Furthermore, rapid urbanisation leads to disproportionate development of infrastructure and greenery, thus significantly reducing major cities' adaptive capacity. Policies should consider and be adjusted to address these common trends of change to enhance adaptability to heatwave and to strengthen Vietnam's overall climate change policies.

\section{Limitations and recommendations for further work}

We acknowledge some limitations of this study. First, the assessment of this study is limited to past health vulnerability to heatwaves rather than current and future vulnerability. It would be warranted to update the data relating to heatwaves and health in the coming years, and to integrate the vulnerability map into the existing surveillance system at the national scale. Second, this study only focusses on heatwaves but not other climate change events such as storm, drought or floods. The study could provide a more realistic basis for policy makers if it were extended to cover other climate change exposure vulnerability indices. Third, the indicators of this study were collected by subjective processes, including indicator selection, standardisation and weighting methods. The validity and reliability of the vulnerability index needs to be assessed. A method for assessing the validity of vulnerability is to look at correlations between vulnerability and past disaster data. Lack 
of some important indicators (e.g. air conditioning and other cooling solutions) also made the limitation of this assessment. Finally, the study missed to conduct sensitivity analysis to test the differences of vulnerability at different scales (i.e. district, commune level) and using different weighting methods due to lack of data. We should consider the sensitivity analyses in the future study. In addition, the future assessment should also consider taking advantage of data from expert stakeholders to improve the methodological approach and intellectual contributions to this aspect.

\section{Conclusions}

This study identified some "hotspots" of health vulnerability due to heatwaves, including Vietnam's Southeast, Central Highlands, and South Central Coast provinces. This study provides useful information to policymakers on how the health vulnerability resulting from heatwaves varies throughout the country. It finds that using AI, SI, and EI to assess vulnerability from heatwave events could be helpful to determine resource-allocation and for planning appropriate interventions to minimise the impact of heatwaves.

\section{Acknowledgement}

DP, CH and TND were supported by the Asia-Pacific Network for Global Change Research (CRRP2016-10MY-Huang). 
Aubrecht, C. and D. Ozceylan (2013). "Identification of heat risk patterns in the U.S. National Capital Region by integrating heat stress and related vulnerability." Environment International 56: 65-77.

Aubrecht, C. and D. Ozceylan (2013). "Identification of heat risk patterns in the U.S. National Capital Region by integrating heat stress and related vulnerability." Environ Int 56: 65-77. Bao, J., X. Li and C. Yu (2015). "The Construction and Validation of the Heat Vulnerability Index, a Review." Int J Environ Res Public Health 12(7): 7220-7234.

Bassil, K. L., D. C. Cole, R. Moineddin, A. M. Craig, W. Y. Lou, B. Schwartz and E. Rea (2009). "Temporal and spatial variation of heat-related illness using 911 medical dispatch data." Environ Res 109(5): 600-606.

Campbell, S., T. A. Remenyi, C. J. White and F. H. Johnston (2018). "Heatwave and health impact research: A global review." Health Place 53: 210-218.

Chaudhry, P. and G. Ruysschaert (2008). "Climate Change and Human Development in Vietnam. UNDP Human Development Report Office OCCASIONAL PAPER."

Dong, W., Z. Liu, L. Zhang, Q. Tang, H. Liao and X. e. Li (2014). "Assessing Heat Health Risk for Sustainability in Beijing's Urban Heat Island." Sustainability 6(10): 7334-7357.

Ebi, K. L., K. A. Exuzides, E. Lau, M. Kelsh and A. Barnston (2004). "Weather changes associated with hospitalizations for cardiovascular diseases and stroke in California, 19831998." Int J Biometeorol(49): 48-58.

Field, C. B., V. R. Barros, D. J. Dokken, M. D. Mastrandrea, K. J. Mach, T. E. Bilir, K. L. Ebi and M. Chatterjee (2014). Climate Change 2014: impacts, adaptation and vulnerablity. Contribution of working group II to the fifth assessment report of the Intergovernmental panel on climate change. UK., Cambridge University Press C.

Gasparrini, A., Y. Guo, M. Hashizume, E. Laviqne, A. Anobetti, J. Swartz, A. Tobias, S. Tong, J. Rocklov, B. Forsberg, M. Leone, M. D. Sario, M. L. Bell, Y. L. Guo, C. F. Wu, H. Kan, S. M. Yi, M. d. S. Z. Stagliorio, P. H. Saldiva, Y. Honda, H. Kim and B. Amstrong (2015). "Mortality risk attributable to high and low ambian temperature: a multicountry observational study." Lancet S0140-6736(14): 62114-62110.

Giang, P. N., D. V. Dung, K. B. Giang, H. V. Vinh and J. Rocklov (2014). "The effect of temperature on cardiovascular disease hospital admission among elderly people in Thai Nguyen Province, Vietnam." Global Health Action 7: 23649.

GSO (2014). "Genral Statistics Office: Statistical Yearbook of Vietnam 2012 and 2014. Statistical Publishing House, Hanoi. Avaialble at:

https://www.gso.gov.vn/Default_en.aspx?tabid=491."

Guo, Y., A. Gasparrini, B. Amstrong, S. Li, B. Tawatsupa, A. Tobias, E. Laviqne, M. d. Z. S. Coelho, M. Leone, X. Pan, S. Tong, L. Tia, H. Him, M. Hashizume, Y. Honda, Y. L. Guo, C. F. Wu, K. Punnasiri, S. M. Yi, O. Michelozzi, P. H. Saldiva and G. William (2014). "Global variation in the effects of ambient temperature on mortality: a systematic evaluation." Epidemiology 25(6): 781-789.

He, C., L. Ma, L. Zhou, H. Kan, Y. Zhang, W. Ma and B. Chen (2019). "Exploring the mechanisms of heat wave vulnerability at the urban scale based on the application of big data and artificial societies." Environ Int 127: 573-583.

Hondula, D. M. and A. G. Barnett (2014). "Heat-Related Morbidity in Brisbane, Australia: Spatial Variation and Area-Level Predictors." Environmental Health Perspective 122(8): 831-836.

Hondula, D. M., R. E. Davis, M. J. Leisten, M. V. Saha, L. M. Veazey and C. R. Wegner (2012). "Fine-scale spatial variability of heat-related mortality in Philadenphia Country, USA, from 1983-2008: a case-series analysis." Environmental Health 11: 1-11. HSY (2013). "Health Statistic Yearbook. Vietnam Ministry of Health." 
Huang, C., A. G. Barnett, X. Wang and S. Tong (2012). "Effects of extreme temperatures on years of life lost for cardiovascular deaths: a time-series study in Brisbane, Australia."

54 Circulation 5: 609-614. Huang, C., A. G. Barnett, X. Wang, P. Vaneckova, G. FitzGerald and S. Tong (2011). "Projecting future heat-related mortality under climate change scenarios: a systematic review." Environ Health Perspect 119: 1681-1690.

INPONRE (2009). "Vietnam Assessment Report On Climate Change (VARCC). IN: http://www.unep.org/pdf/dtie/VTN_ASS_REP_CC.pdf."

Knowlton, K., M. Rotkin-Ellman, G. King, H. G. Margolis, D. Smith, G. Solomon, R. Trent and P. English (2009). "The 2006 California Heat Wave: Impacts on Hospitalizations and

Emergency Department Visits." Envi Health Persp 117(1): 61-67.

Lee, H. S., H. V. Nguyen, V. S. Nam, M. Lee, S. Won, P. P. Pham and D. Grace (2017). "Seasonal patterns of dengue fever and associated climate factors in 4 provinces in Vietnam from 1994 to 2013." BMC Infect Dis 17(1): 218.

Matthies, F., G. Bickler, N. C. Marı 'n and S. Hales (2008). Heat-health action plans: guidance. Geneva., World Health Organization.

McCarthy, J. J., O. F. Canziani, N. A. Leary, D. J. Dokken and K. S. White (2001). Climate change 2001: impacts, adaptation, and vulnerability: contribution of Working Group II to the third assessment report of the Intergovernmental Panel on Climate Change, Cambridge University Press.

Michelozzi, P., G. Accetta, M. Desario and et al (2009). "High temperature and hospitalizations for cardiovascular and respiratory causes in 12 European cities." American of Respiratory and Critical Care Medicine 179(5): 383-389.

Milazzo, A., L. C. Giles, Y. Zhang, A. P. Koehler, J. E. Hiller and P. Bi (2016). "The effect of temperature on different Salmonella serotypes during warm seasons in a Mediterranean climate city, Adelaide, Australia." Epidemiol Infect 144(6): 1231-1240.

MONRE (2008). Ministry of Natural Resources and Environment: Target programme to respond to climate change.

MONRE (2009). "Ministry of Natural Resources and Environment. Climate change scenario, sea level rise for Vietnam."

MONRE (2013). "Ministry of Natural Resources and Environment: Documentation to assess the impact of climate change and adaptation measures, Hanoi."

MONRE (2016). "Ministry of Natural Resources and Environment: Climate change scenarios and sea level rise for Vietnam."

Mu, E. and M. Pereyra-Rojas (2017). Understanding the analytic Hierarchy process. Practical Decision Making, Springer: 7-22.

Ngo, D. T., C. Kieu, M. Thatcher, L. D. Nguyen and V. T. Phan (2014). "Climate projections for Vietnam based on regional climate models." Climate Research 60(3): 199-213.

Oppenheimer, M., M. Campos, R. Warren, J. Birkmann, G. Luber, B. O'neill and K. Takahashi (2014). "Emergent risks and key vulnerabilities." Risk 19: 1.

Page, L. A., S. Hajat, R. s. Kovats and L. M. Howard (2012). "Temperature-related deaths in people with psychosis, dementia and substance misuse." The British Journal of psychiatry: the journal of mental science 200(6): 485-490.

Parry, P. M., M. L. Parry, I. P. o. C. Change, G. d. e. i. s. l. é. d. c. W. G. II., I. P. o. C. C. W. G. I., I. P. o. C. C. W. G. II., O. Canziani, J. Palutikof, P. Van der Linden and C. Hanson (2007). Climate Change 2007 - Impacts, Adaptation and Vulnerability: Working Group II Contribution to the Fourth Assessment Report of the IPCC, Cambridge University Press. Phung, D., C. Chu, S. Rutherford, H. L. Nguyen, C. M. Do and C. Huang (2017). "Heatwave and risk of hospitalization: A multi-province study in Vietnam." Environmental Pollution. Phung, D., Y. Guo, H. T. L. Nguyen, S. Rutherford, S. Baum and C. Chu (2016). "High temperature and risk of hospitalizations, and effect modifying potential of socio-economic 
conditions: A multi-province study in the tropical Mekong Delta Region." Environment International 92-93: 77-86.

Phung, D., Y. Guo, H. T. L. Nguyen, S. Rutherford, S. Baum and C. Chu (2016). "High temperature and risk of hospitalizations, and effect modifying potential of socio-economic conditions: A multi-province study in the tropical Mekong Delta Region." Environment International 92-93(2016): 77-86.

Phung, D., Y. Guo, P. Thai, S. Rutherford, X. Wang, M. Nguyen, C. M. Do, N. H. Nguyen, N. Alam and C. Chu (2015). "The effects of high temperature on cardiovascular admissions in the most populous tropical city in Vietnam." Environmental Pollution In Press. Phung, D., C. Huang, S. Rutherford, C. Chu, X. Wang, M. Nguyen, N. H. Nguyen and C. M. Do (2014). "Identification of the prediction model for dengue incidence in Can Thoi city, a Mekong Delta area in Vietnam." Acta Tropica 141(2014): 88-96.

Phung, D., C. Huang, S. Rutherford, C. Chu, X. Wang, M. Nguyen, N. H. Nguyen, C. M. Do and T. H. Nguyen (2015). "Temporal and spatial patterns of diarrhoea in the Mekong Delta area, Vietnam." Epidemiol. Infect. 2015: 1-10.

Phung, D. T., S. Rutherford, C. Chu, X. Wang, M. Nguyen, C. M. Do, T. H. Nguyen and C. Huang (2015). "Temperature as a risk factor for hospitalisations among young children in the Mekong Delta area, Vietnam." Occup Environ Med 0: 1-7.

RCRPH (2011). Research Center for Rural Population and Health: Mapping out vulnerable areas and population due to adverse health impacts of climate change in Viet Nam, WHO. Reid, M., C. O'Neill, S. Gronlund, S. Brines, D. Brown, A. Diez-Roux and et al (2009). "Mapping community determinants of heat vulnerability." Environmental Health Perspectives 117(11): 1730-1736.

Rey, G., A. Fouillet, P. Bessemoulin, P. Frayssinet, A. Dufour, E. Jougla and D. Hemon (2009). "Heat exposure and socio-economic vulnerability as synergistic factors in heat-wave-related mortality." Eur J Epidemiol 24(9): 495-502.

Turner, L. R., A. G. Barnett, D. Connell and S. Tong (2012). "Ambient temperature and cardiorespiratory morbidity: a systematic review and meta-analysis." Epidemiology 23(4): 594-606.

UNDP (2016). United Nations Development Programme: Economics of climate change adaptation: agriculture sector analysis for Vietnam. United States Agency for International Development's., USAID: 15-19.

UNEP (2009). Vietnam Assessment Report on Climate Change. IN:

http://www.unep.org/climatechange/adaptation.

Vincent, K. (2004). "Creating an Index of Social Vulnerability to Climate Change in Africa." VN GSO (2008). "Report on update population census in Vietnam.".

Whitaker, R. (2007). "Validation examples of the analytic hierarchy process and analytic network process." Mathematical and Computer Modelling 46(7-8): 840-859.

Xiang, J., A. Hansen, Q. Liu, M. X. Tong, X. Liu, Y. Sun, S. Cameron, S. Hanson-Easey, G. S. Han, C. Williams, P. Weinstein and P. Bi (2018). "Association between malaria incidence and meteorological factors: a multi-location study in China, 2005-2012." Epidemiol Infect 146(1): 89-99.

Xuan, T. T. L., T. Egondi, L. T. Ngoan, T. T. D. Toan and L. T. Huong (2014). "Seasonality in mortality and its relationship to temperature among the older population in Hanoi, Vietnam." Global Health Action 7: 23115.

Xuan, T. T. L., P. V. Hau, D. T. Thu and T. T. D. Toan (2014). "Estimates of meteorological variability in association with dengue cases in a coastal city in nothern Vietnam: an ecological study." Global Health Action 7: 23119.

Yang, X., L. Li, J. Wang, J. Huang and S. Lu (2015). "Cardiovascular mortality associated with low and high temperatures: determinants of inter-region vulnerability in china." Int I Environ Res Public Health. 12(6): 5918-1933. 
154 Yusuf, A. A. and H. Francisco (2009). "Climate Change Vulnerability Mapping for Southeast 155 Asia. Economy and Environment Program for Southeast Asia (EEPSEA). In:

156 http://www.eepsea.org.".

157 Zhu, Q., T. Liu, H. Lin, J. Xiao, Y. Luo, W. Zeng, S. Zeng, Y. Wei, C. Chu, S. Baum, Y. Du and W. Ma 158 (2014). "The spatial distribution of health vulnerability to heat waves in Guangdong 159 Province, China." Global Health Action 7: 25051.

160

161

162

163

164

165

166

167

168

169

170

171

172

173

174

175

176

177

178

179

180

181

182

183

184

185

186

187

188

189

190

191 


\begin{tabular}{|c|c|c|c|c|c|}
\hline \multirow[t]{2}{*}{ Indicators } & \multirow{2}{*}{$\begin{array}{c}\text { Data } \\
\text { source }\end{array}$} & \multirow{2}{*}{$\begin{array}{c}\text { Time of } \\
\text { data } \\
\text { collection }\end{array}$} & \multicolumn{3}{|c|}{ Value } \\
\hline & & & Min & Median & $\operatorname{Max}$ \\
\hline \multicolumn{6}{|l|}{ Sensitivity Index (SI) } \\
\hline Population density (persons $/ \mathrm{km}^{2}$ ) & GSOV & 2014 & 47 & 276 & 3888 \\
\hline $\begin{array}{l}\% \text { Population younger than } 15 \text { or older } \\
\text { than } 60\end{array}$ & GSOV & 2014 & 28.6 & 39.9 & 47.8 \\
\hline$\%$ Female population & GSOV & 2014 & 46.7 & 50 & 52 \\
\hline$\%$ Urban population & GSOV & 2014 & 10.4 & 22.9 & 87 \\
\hline $\begin{array}{l}\% \text { Population over the age of } 15 \text { who are } \\
\text { illiterate }\end{array}$ & GSOV & 2014 & 1.5 & 5.4 & 40.8 \\
\hline$\%$ Households in poverty & GSOV & 2014 & 0 & 8 & 31.5 \\
\hline Unemployment rate $(\%)$ & GSOV & 2014 & 1.9 & 4.3 & 7.1 \\
\hline $\begin{array}{l}\% \text { Households with lower access to safe } \\
\text { water }\end{array}$ & VPHC & 2009 & 0.3 & 11.8 & 82.8 \\
\hline \multicolumn{6}{|l|}{ Adaptive Capacity Index (AI) } \\
\hline Health staff per 10,000 people & VHSYB & 2014 & 1 & 3 & 5 \\
\hline$\%$ Households with air conditioning & VPHC & 2009 & 0.2 & 2.2 & 21.7 \\
\hline$\%$ Blue spaces & $\begin{array}{l}\text { MODIS / } \\
\text { NASA }\end{array}$ & $\begin{array}{c}2001- \\
2010\end{array}$ & 0.1 & 2.7 & 90.2 \\
\hline
\end{tabular}

GSOV: General Statistics Office of Vietnam

194 VHSY: Vietnam Health Statistical Yearbook

195 VPHC: The 2009 Vietnam Population and Housing Census

196 MODIS: Moderate Resolution Imaging Spectroradiometer 
208 Table 2. AHP weight of indicators

\begin{tabular}{|c|c|c|c|c|c|c|c|c|c|c|c|c|}
\hline \multirow[t]{2}{*}{ Indicators } & \multicolumn{10}{|c|}{ Experts } & \multirow{2}{*}{$\begin{array}{c}\text { Mean } \\
\text { weight }\end{array}$} & \multirow[b]{2}{*}{ SD } \\
\hline & E1 & E2 & $\mathbf{E 3}$ & $\mathbf{E 4}$ & $\mathbf{E 5}$ & E6 & E7 & E8 & E9 & E10 & & \\
\hline \multicolumn{13}{|l|}{ Sensitivity } \\
\hline$\%$ population $>65$ & 0.205 & 0.197 & 0.169 & 0.261 & 0.237 & 0.172 & 0.125 & 0.067 & 0.164 & 0.239 & 0.1836 & 0.058 \\
\hline$\%$ population $<5$ & 0.149 & 0.197 & 0.169 & 0.057 & 0.237 & 0.092 & 0.125 & 0.106 & 0.26 & 0.239 & 0.1631 & 0.069 \\
\hline$\%$ low access to safe water & 0.198 & 0.065 & 0.169 & 0.057 & 0.153 & 0.183 & 0.125 & 0.264 & 0.178 & 0.028 & 0.1419 & 0.073 \\
\hline Population density & 0.116 & 0.197 & 0.169 & 0.166 & 0.076 & 0.115 & 0.125 & 0.17 & 0.113 & 0.162 & 0.141 & 0.037 \\
\hline$\%$ poverty & 0.099 & 0.07 & 0.169 & 0.166 & 0.163 & 0.097 & 0.125 & 0.067 & 0.051 & 0.064 & 0.1071 & 0.046 \\
\hline$\%$ population in urban & 0.123 & 0.12 & 0.064 & 0.099 & 0.058 & 0.097 & 0.125 & 0.17 & 0.024 & 0.064 & 0.0944 & 0.043 \\
\hline$\%$ female population & 0.021 & 0.07 & 0.048 & 0.099 & 0.017 & 0.041 & 0.125 & 0.106 & 0.048 & 0.134 & 0.0709 & 0.043 \\
\hline$\%$ illiterate & 0.047 & 0.042 & 0.023 & 0.036 & 0.03 & 0.097 & 0.063 & 0.024 & 0.051 & 0.042 & 0.0453 & 0.022 \\
\hline$\%$ unemployment & 0.041 & 0.042 & 0.023 & 0.057 & 0.031 & 0.104 & 0.063 & 0.024 & 0.113 & 0.028 & 0.0526 & 0.032 \\
\hline \multicolumn{13}{|l|}{ Adaptive capacity } \\
\hline $\begin{array}{l}\% \text { households that have } \\
\text { air conditioning }\end{array}$ & 0.49 & 0.164 & 0.462 & 0.6 & 0.667 & 0.333 & 0.25 & 0.164 & 0.4 & 0.557 & 0.408 & 0.178 \\
\hline $\begin{array}{l}\text { Health related status } \\
\text { (health staff per 10000) }\end{array}$ & 0.312 & 0.539 & 0.462 & 0.2 & 0.167 & 0.333 & 0.5 & 0.297 & 0.2 & 0.123 & 0.313 & 0.146 \\
\hline Vegetation index & 0.198 & 0.297 & 0.077 & 0.2 & 0.167 & 0.333 & 0.25 & 0.539 & 0.4 & 0.32 & 0.278 & 0.178 \\
\hline
\end{tabular}


Figures

233 Figure 1. Conceptual vulnerability assessment framework

234 Figure 2. Total number of heatwave days during the study period (2005-2017) in each province

235 (2A), Spatial distribution of Sensitivity (2B), and Adaptive capacity (2C)

236 Figure 3. Spatial distribution of Vulnerability Index (VI) 
